\title{
Ground Surface Temperature Reconstructions: Using In Situ Estimates for Thermal Conductivity Acquired with a Fiber-Optic Distributed Thermal Perturbation Sensor
}

\author{
Barry M. Freifeld and Stefan Finsterle \\ Lawrence Berkeley National Laboratory, Berkeley, CA, USA \\ Tullis C. Onstott \\ Princeton University, Princeton, NJ, USA \\ Trish Toole \\ Zinifex Canada Inc., Ontario, Canada \\ Lisa M. Pratt \\ Indiana University, Bloomington, IA USA
}

\begin{abstract}
We have developed a borehole methodology to estimate formation thermal conductivity in situ with a spatial resolution of one meter. In parallel with a fiber-optic distributed temperature sensor (DTS), a resistance heater is deployed to create a controlled thermal perturbation. The transient thermal data is inverted to estimate the formation's thermal conductivity. We refer to this instrumentation as a Distributed Thermal Perturbation Sensor (DTPS), given the distributed nature of the DTS measurement technology. The DTPS was deployed in permafrost at the High Lake Project Site $\left(67^{\circ} 22^{\prime} \mathrm{N}, 110^{\circ} 50^{\prime} \mathrm{W}\right)$, Nunavut, Canada. Based on DTPS data, a thermal conductivity profile was estimated along the length of a wellbore. Using the thermal conductivity profile, the baseline geothermal profile was then inverted to estimate a ground surface temperature history (GSTH) for the High Lake region. The GSTH exhibits a 100-year long warming trend, with a present-day ground surface temperature increase of $3.0 \pm 0.8^{\circ} \mathrm{C}$ over the longterm average.
\end{abstract}

\section{Introduction}

Given that global climate models predict the greatest increases in temperature at Arctic latitudes, changes in permafrost are increasingly looked upon as a harbinger of climate change (Anisimov et al., 2007). Borehole thermal profiles provide information on past ground surface temperature histories (GSTH) not available from atmospheric temperature records collected prior to the twentieth century (Lachenbruch \& Marshall, 1986; Harris \& Chapman, 1997). To invert thermal profile data for estimating GSTH, thermal properties need to be constrained. Prior climate reconstruction studies have either used laboratory measurements performed on drill cores or cutting fragments, or have used estimates based on lithologic descriptions (Taylor et al., 2006; Majorowicz and Safanda, 2001). Imperfect drill core recovery and the effort required to perform numerous laboratory measurements usually dictate simplification of the thermal conductivity field used in the analyses. 
In studies for which drill core has not been recovered, thermal conductivity is assigned based on published values for similar facies. Chouinard et al. (2007) estimated GSTH based on temperatures in three closely spaced boreholes using one of three thermal conductivity values to represent the local lithology: argillite $\left(2.4 \mathrm{~W} \mathrm{~m}^{-1} \mathrm{~K}^{-1}\right)$, peridotite/gabbro $\left(2.8 \mathrm{~W} \mathrm{~m}^{-1} \mathrm{~K}^{-1}\right)$ and basalt (3.1 W m $\mathrm{W}^{-1} \mathrm{~K}^{-1}$ ). However, when detailed thermal conductivity profiles have been estimated based on borehole temperature profiles, thermal conductivity is usually highly variable (Henninges et al., 2005; Mwenifumbo, 1993).

We developed a methodology to determine thermal conductivity with depth with a spatial resolution of 1 meter by combining a fiber-optic distributed temperature sensor (DTS) with a borehole length electrical resistance heater. We refer to the coupled instruments as a distributed thermal perturbation sensor (DTPS). The DTPS methodology is similar to the Temperature Recovery Method proposed by Günzel and Wilhelm (1999), although our use of an electrical heater provides a more precisely controlled thermal disturbance than circulation of fluid within the wellbore.

In the summer of 2007 we installed a multifunctional borehole observatory at the High Lake Project Site $\left(67^{\circ} 22^{\prime}\right.$ N, $\left.110^{\circ} 50^{`} \mathrm{~W}\right)$, in Nunavut, Canada, with the aim of acquiring a broad spectrum of environmental data. In addition to installing a DTPS, a pneumatic packer was set above the base of the permafrost. A U-tube geochemical sampling system acquired fluid samples for delineating gas concentration, $\mathrm{pH}$, pe, microbial abundance and community structure and activity, as well as isolating pristine subpermafrost brine for future studies (Freifeld et al., 2005). A pressure-temperature sensor collocated with the U-tube sampling inlet facilitated estimation of hydraulic conductivity. This paper focuses on the data collected using the DTPS, the in situ estimates for thermal conductivity, and our predicted GSTH.

\section{High Lake Site and Observatory Description}

\section{Site description}

The High Lake Project Site is located in an Archaen mafic volcanic belt, with permafrost extending down to $460 \mathrm{~m}$ on a mining exploratory lease originally purchased by Wolfden Resources and currently operated by Zinifex Canada Inc. All of the work was conducted within a $75 \mathrm{~mm}$ diameter borehole (designated HL03-28), which was initially drilled in 2003 to a length of $335 \mathrm{~m}$ (depth $304 \mathrm{~m}$ ) as part of Wolfden Resource's characterization of base metals for potential economic extraction from the High Lake volcanogenic massive sulfide deposit. In July 2006, our project team cored continuously to lengthen HL03-28 to $535 \mathrm{~m}$. After removing an ice blockage that formed in the borehole during the previous season, we installed a permanent borehole observatory.

\section{Borehole observatory}


The High Lake borehole observatory targeted both the permafrost region for geothermal investigation and the subpermafrost formation for estimation of hydrologic properties and collection of fluid samples. The instrumentation at the bottom of the borehole, consisting of a pneumatic packer, a U-tube sampling system with a sample fluid reservoir, and a pressuretemperature sensor, are collectively referred to as the bottom hole assembly (BHA). The fluid, electrical, and fiber-optic lines running between the BHA and the surface are referred to as the deployment string. The downhole pressure/temperature transducers serve as a calibrated reference point for the DTS.

The DTPS deployed at High Lake consisted of an HDPE jacketed multimode fiber-optic cable that runs from the top of the packer fluid reservoir up to a DTS (DTS; Agilent Technologies Manufacturing GmbH \& Co. KG, Model N4385A, Böblingen, Germany) located at the surface. The DTS uses a laser backscattering technique to measure temperature with a $1 \mathrm{~m}$ spatial resolution along the fiber. A description of DTS technology as applied to wellbore temperature monitoring can be found in Hurtig et al. (1994). Parallel to the fiber-optic cable is a two-conductor 14 AWG direct burial (outdoor) cable shorted at the bottom, which provides uniform heating along the length of the well when current is applied. Following the wellbore completion process, the temperature was allowed to equilibrate for 1 month before we acquired a baseline thermal profile and started acquiring data with the DTPS.

\section{Results}

\section{Permafrost thickness and hydrostatic head}

Our baseline thermal profile provides the most accurate measurement of permafrost thickness in this region, as other nearby estimates by the Geological Survey of Canada are extrapolated from much shallower boreholes (e.g., Taylor et al., 1998). A linear extrapolation through the lower $120 \mathrm{~m}$ of DTS data through the pressure-temperature sensor (Figure 1), indicates that the base of the permafrost $\left(0^{\circ} \mathrm{C}\right.$ isotherm $)$ is at $458 \pm 5 \mathrm{~m}$. The depth uncertainty is based upon propagating a temperature error of $\pm 0.1^{\circ} \mathrm{C}$ into the depth estimate. A small correction $\left(+0.025^{\circ} \mathrm{C}\right)$ has been applied to account for the thermal perturbation created near the base of the well during the wellbore completion process, following the method suggested by Lachenbruch and Brewer (1959). By plotting the temperatures measured after wellbore completion as a function of $\log _{\mathrm{e}}(t /(t-s))$, where $t$ is the time elapsed since wellbore completion and $s$ is the duration of the thermal perturbation (assumed to be 1.25 days), we correct for the effect of cooler water being introduced deeper in the borehole during the completion process.

The steady-state subpermafrost hydrostatic pressure can also be estimated by plotting pressure as a function of $\log _{\mathrm{e}}(t /(t-$ s) ) — referred to as a Horner Plot in well test literature. Using the pressure data from the Level Troll pressure-temperature 
sensor, we determined the hydrostatic pressure at a depth of $430 \mathrm{mbgs}$ to be $3420 \mathrm{kPa}$. This is equivalent to a freshwater head of $349 \mathrm{~m}$, or a water table at 81 mbgs.

\section{Thermal perturbation measurements}

To conduct the DTPS measurement, we energized the heater cable $(16.8 \mathrm{~W} / \mathrm{m}$ for 43 hours followed by $20.5 \mathrm{~W} / \mathrm{m}$ for 21 hours) and obtained thermal profiles at 15-minute intervals to record the temperature transient during heating. After 64 hours of monitoring the heating, the generator was turned off, and cooling was monitored for an additional 58 hours. To interpret the acquired thermal transients, we used a one-dimensional radial model explicitly incorporating the fluid-filled borehole and steel casing, surrounded by rock with homogeneous thermal properties, to invert cooling data. Given the very low matrix porosity measured on HL03-28 core $(<0.01 \%)$ and the $15 \% \mathrm{CaCl}_{2}$ brine solution used to fill the borehole, the latent heat of freezing of water was not incorporated in the model. Heating data are not used, because small variations in spatial distance between the fiber-optic cable and the heating cable create large differences in temperatures. During cooling, however, conduction of heat tends to homogenize temperatures near the wellbore, making the simulations insensitive to the separation between the heating cable and monitoring fiber.

Figure 2 shows modeled cooling transients as a function of rock thermal conductivity, with data shown for selected depths. The model data are shown as lines and the measurements are shown as points. Using the one-dimensional radial model to invert the DTPS data, thermal conductivity is estimated along the wellbore with a spatial resolution equivalent to the $1 \mathrm{~m}$ resolution of the DTS. Although heat capacity is variable, the variation is considerably less than for thermal conductivity, and a constant value of $750 \mathrm{~J} / \mathrm{kg}^{\circ} \mathrm{C}$ was chosen (Vosteen and Schellschmidt, 2003). The thermal conductivity estimates shown in Figure 3 are consistent with the borehole lithology and literature values (Clauser \& Huenges, 1995), in which metavolcanic strata of intermediate to mafic composition contain thin, mineralized zones with $15 \%$ to $50 \%$ pyrite.

\section{Ground surface temperature history}

The temperature profile measured at any given time depends on (1) the geothermal heat flux, (2) conductive and convective heat transfer properties, and (3) the GSTH. It is obvious that inferring GSTH from a temperature profile is an inherently illposed inverse problem. We mitigate non-uniqueness by making the following assumptions: (1) the geothermal heat fluxwhile unknown - has been constant with time over the last few thousand years; (2) convective heat flow is zero due to the absence of moving fluids in the permafrost region; (3) neglecting topographic impacts and lateral heterogeneity in thermal properties, conductive heat flow is one-dimensional; and (4) the thermal conductivities are accurately represented by the profile 
shown in Figure 3. In addition, the inverse problem is mildly regularized by penalizing large amplitudes in GSTH fluctuations around an unknown mean surface temperature.

The numerical inversion code iTOUGH2 (Finsterle, 2004) was used to estimate GSTH up to year 2000 by automatically matching the calculated to the observed baseline temperature profile (Figure 1). Surface temperature was parameterized by specifying the rate of temperature increase or decline at every 100 years. In addition, the geothermal heat flux at the bottom of the model is an adjustable parameter. Finally, the mean temperature over the 2000-year simulation period is added as a parameter to be estimated. Deviations of calculated surface temperatures from this mean are mildly penalized by specifying the mean temperature as a reference data with a prior uncertainty of $5^{\circ} \mathrm{C}$. Assuming that we have some prior knowledge about the mean surface temperature—even with large uncertainty—provides the regularization needed to avoid large fluctuations in the estimated, time-dependent surface heat fluxes. A total of 100 temperature data measured in borehole HL03-28 between a depth of $30 \mathrm{~m}$ and $400 \mathrm{~m}$ are specified as calibration points with an uncertainty of $0.1^{\circ} \mathrm{C}$. A weighted least-squares objective function was used to asses the deviations between the measured and calculated profile temperature, and between the estimated and calculated mean surface temperature. The minimum of the objective function was identified using the Levenberg-Marquardt algorithm.

The match obtained (Figure 1) is consistent with the expected measurement error, with a mean temperature residual of $0.1^{\circ} \mathrm{C}$. The inferred GSTH is shown in Figure 4. The average surface temperature at High Lake over the past 1000 years is estimated to be $-9.3 \pm 0.2^{\circ} \mathrm{C}$. This estimation uncertainty is sufficiently small so that the recent temperature increase to $-6.3 \pm 0.7^{\circ} \mathrm{C}$ can be identified as statistically significant. The ground surface temperature is seen to decline $0.6^{\circ} \mathrm{C}$ between years 1000 to a minimum at 1860, similar to the trend noted by Marjorwicz et al. (2004) for their inversion of temperature data from 61 wells in Northern Canada (north of $60^{\circ} \mathrm{N}$ ). The ground surface temperature increase at High Lake from the Little Ice Age minimum at year 1860 to present is estimated to be $3.4^{\circ} \mathrm{C}$.

The vertical thermal flux at borehole HL03-28 is estimated to be $67 \pm 1 \mathrm{~mW} / \mathrm{m}^{2}$, which is greater than the $54 \pm 4 \mathrm{~mW} / \mathrm{m}^{2}$ estimated at the Muskox Intrusion, $200 \mathrm{~km}$ west of High Lake, by Beck and Sass (1966) and the value of $46 \pm 6 \mathrm{~mW} / \mathrm{m}^{2}$ reported for two wells $320 \mathrm{~km}$ south of High Lake by Mareschal et al. (2004) at Lac du Gras, Nunuvut, Canada. It is also greater than the value of $54.1 \mathrm{~mW} / \mathrm{m}^{2}$ estimated by inversion of thermobarometric data by Russell \& Kopylova (1999) at the Jericho Kimberlite Pipes located $230 \mathrm{~km}$ southwest of High Lake. The higher heat flow at High Lake can possibly be attributed to the effect of the massive volcaniclastic sulfide deposit, which can act as a conduit for conduction of heat to the surface.

The reduced gradient in the thermal profile at depths shallower than $150 \mathrm{~m}$ at HL03-28 is consistent with other studies investigating GSTH in Canada. Similar changes are apparent in Northern Canadian temperature logs compiled by Marjorwicz et al. (2004), Superior Province temperature logs (Shen \& Beck, 1992), temperature logs from three boreholes in northern 
Quebec (Chouinard et al., 2007), and also in temperature profiles reported in the Canadian Arctic Archipelago (Taylor et al., 2006). However, without more detailed information on the three-dimensional shape of the High Lake ore body, which could influence lateral heat flux, and/or the regional history of snow cover, which would impact vertical heat flux (Stieglitz et al., 2003), it is impossible to know how much of the observed warming can be attributed to increases in arctic air temperatures.

\section{Conclusions}

We have deployed a multifunctional borehole observatory at the High Lake Project Site, which includes a bottomhole assembly for subpermafrost geochemical sampling using a U-tube sampler located beneath a packer, and a pressure/temperature sensor for monitoring hydrologic conditions. The deployment lines contained a distributed thermal perturbation sensor (DTPS), consisting of a fiber-optic cable for distributed temperature measurements, and a heat trace cable to uniformly heat the wellbore.

Given the interest in using borehole temperature profiles as an indicator of paleoclimate, we have demonstrated a methodology for using the DTPS data for estimating formation thermal conductivity as a function of depth with meter-scale resolution. Having in situ estimates for thermal properties can reduce uncertainty in inverting borehole temperature profiles, leading to more accurate delineations of ground surface temperature history (GSTH). While the inversion of GSTH from temperature logs is non-unique and with the limitation that we lack knowledge of changes in snow cover, warming of $3.0 \pm 0.8^{\circ} \mathrm{C}$ over the longterm average appears in the HL03-28 temperature record.

\section{Acknowledgments}

This work was supported by a grant from the NASA Astrobiology Institute (NASA NNA04CC03A) and performed under DOE-LBNL contract number, DE-AC02-05CH11231. Additional support was provided through the Geological Survey of Finland, Espoo, Finland, POSIVA Oy, Finland, SKB, Sweden, and the Nuclear Waste Management Organization, Ontario, Canada. The authors thank Adam Johnson, Brian Holden, Peter Suchecki and Eric Chan for assistance during field equipment installation and operation and Christine Doughty and Teamrat Ghezzehei for their thorough manuscript reviews. The authors wish to thank Jason Rickard and Zinifex Canada Inc. for providing access to the High Lake Project Site and acknowledge the generous loan of the Agilent DTS by Agilent Technologies.

\section{References}


Anisimov, O. A., D. G., Vaughan, T. V. Callaghan, C. Furgal, H. Marchant, T. D. Prowse, H. Vilhjálmsson, and J. E. Walsh. (2007), Polar regions (Arctic and Antarctic). Climate Change 2007: Impacts, Adaptation and Vulnerability. Contribution of Working Group II to the Fourth Assessment Report of the Intergovernmental Panel on Climate Change, Parry, M.L., Canziani, O.F., Palutikof, J.P., van der Linden P.J. \& Hanson, C.E. Eds., Cambridge University Press, Cambridge, 653-685.

Beck, A. E., and J. H. Sass (1966), A preliminary value of heat flow at the Muskox Intrusion near Coppermine, N.W.T., Canada, Earth Plan. Sci. Lett., 1, 123-129, doi.org/10.1016/0012-821X(66)90090-2.

Chouinard, C., R. Fortier, and J. -C. Mareschal (2007), Recent climate variation in the subarctic inferred from three borehole temperature profiles in northern Quebec, Canada, Earth Plan. Sc. Lett., 263, 355-369, doi:10.1016/j.eps1.2007.09.017.

Clauser, C. and E. Huenges, (1995), Thermal conductivity of rocks and minerals, in Rock physics and phase relations: a handbook of physical constants, ed. T.J. Ahrens, American Geophysical Union.

Finsterle, S. (2004), Multiphase inverse modeling: Review and iTOUGH2 applications, Vadose Zone J., 3: $747-762$.

Freifeld, B. M., R. C. Trautz, K. K. Yousif, T. J. Phelps, L. R. Myer, S. D. Hovorka, and D, Collins (2005), The U-Tube: A novel system for acquiring borehole fluid samples from a deep geologic $\mathrm{CO}_{2}$ sequestration experiment, J. Geophys. Res., 110, B10203, doi:10.1029/2005JB003735.

Günzel, U. and H. Wilhelm (1999), Estimation of the in-situ thermal resistance of a borehole using the Distributed Temperature Sensing (DTS) technique and the Temperature Recovery Method (TRM), Geothermics 29, 689-700.

Harris, R. N. and D. S. Chapman (1997), Borehole temperatures and a baseline for $20^{\text {th }}$-Century global warming estimates, Science 275, 1618-1621.

Henninges, J., E. Huenges, H. Burkhardt (2005), In situ thermal conductivity of gas-hydrate-bearing sediments of the Mallik 5L-38 well, J. Geophys. Res., 110, B11206, doi:10.1029/2005JB003734.

Hurtig, E., S. Großwig, M. Jobmann, K. Kühn, and P. Marschall (1994), Fibre-optic temperature measurements in shallow boreholes: experimental application for fluid logging, Geothermics 23, 355-364.

Lachenbruch, A. H. and M. Brewer (1959), Dissipation of the temperature effect in drilling a well in arctic Alaska, United States Geological Survey Bulletin 1083-C, 73-109.

Lachenbruch, A. H. and B. V. Marshall (1986), Changing climate: geothermal evidence from permafrost in the Alaskan Arctic, Science 234, 689-696.

Mareschal, J. C., A. Nyblade, H. K. C. Perry, C. Jaupart, and G. Bienfait (2004), Heat flow and deep lithospheric thermal structure at Lac de Gras, Slave Province, Canada, Geophys. Res. Lett., 31, L12611, doi:10.1029/2004GL020133. 
Majorowicz, J. A., W.R. Skinner and J. Safanda (2004), Large ground warming in the Canadian Arctic inferred from inversion of temperature logs, Earth Plan. Sci. Lett., 221, 15-25, doi:10.1016/S0012-821X(04)00106-2.

Majorowicz, J. A. and J. Safanda (2001), Composite surface temperature history from simultaneous inversion of borehole temperatures in western Canadian plains, Global and Planetary Change 29, 231-239.

Mwenifumbo, C. J. (1993), Temperature logging in mineral exploration, J. Appl. Geophy. 30, $297-313$.

Russell, J. K. and M. G. Kopylova (1999), A steady state conductive geotherm for the north central Slave, Canada: Inversion of petrological data from the Jericho Kimberlite pipe, J. Geophys. Res. 104, 7089-7101.

Shen, P. Y., and A. E. Beck (1992), Paleoclimate change and heat flow density inferred from temperature data in the Superior Province of the Canadian Shield, Paleogeogr., Palaeoclimatol., Palaeoecol. (Global Planet. Change Sect.), 98 :143165.

Stieglitz, M., S. J. Déry, V. E. Romanovsky and T. E. Osterkamp (2003), The role of snow cover in the warming of arctic permafrost, Geophys. Res. Lett., 30(13), 1721, doi:10.1029/2003GL017337.

Taylor, A. E., M. M. Burgess, A. S. Judge, V. S. Allen, and A. Wilkinson (1998), Canadian Geothermal Data CollectionDeep permafrost temperatures and thickness of permafrost, in Circumpolar Active Layer Permafrost System (CAPS), version 1.0, CD-ROM, compiled by International Permafrost Association, Data and Information Working Group, CDROM, National Snow and Ice Data Center, University of Colorado, Boulder, Colo.

Taylor, A. E., K. Wang, S. L. Smith, M. M. Burgess, and A. S. Judge (2006), Canadian Arctic permafrost observatories: detecting contemporary climate change through inversion of subsurface temperature time series, J. Geophys. Res. 111, B02411, doi:10.1029/2004JB003208.

Vosteen, H-D. and R. Schellschmidt (2003), Influence of temperature on thermal conductivity, thermal capacity and thermal diffusivity for different types of rocks, Physics and Chem. Earth 28, 499-509, doi.org:10.1016/S1474-7065(03)00069$\mathrm{X}$. 


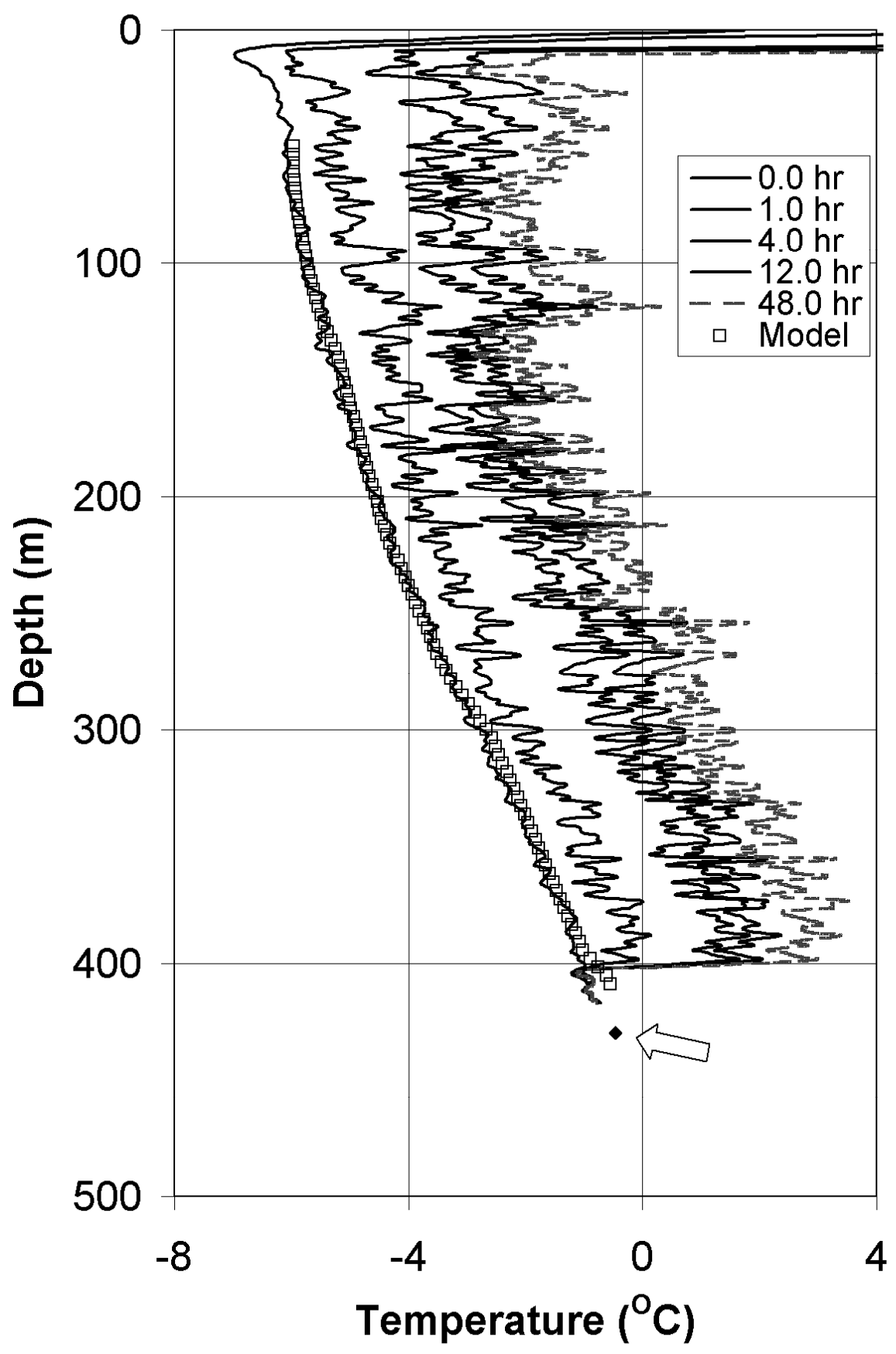

Figure 1. Thermal profiles acquired using a DTS. The lowest profile is the baseline prior to heating and cooling. The match between measured and modeled thermal profile (boxes) incorporates thermal conductivity values derived using DTPS data. 


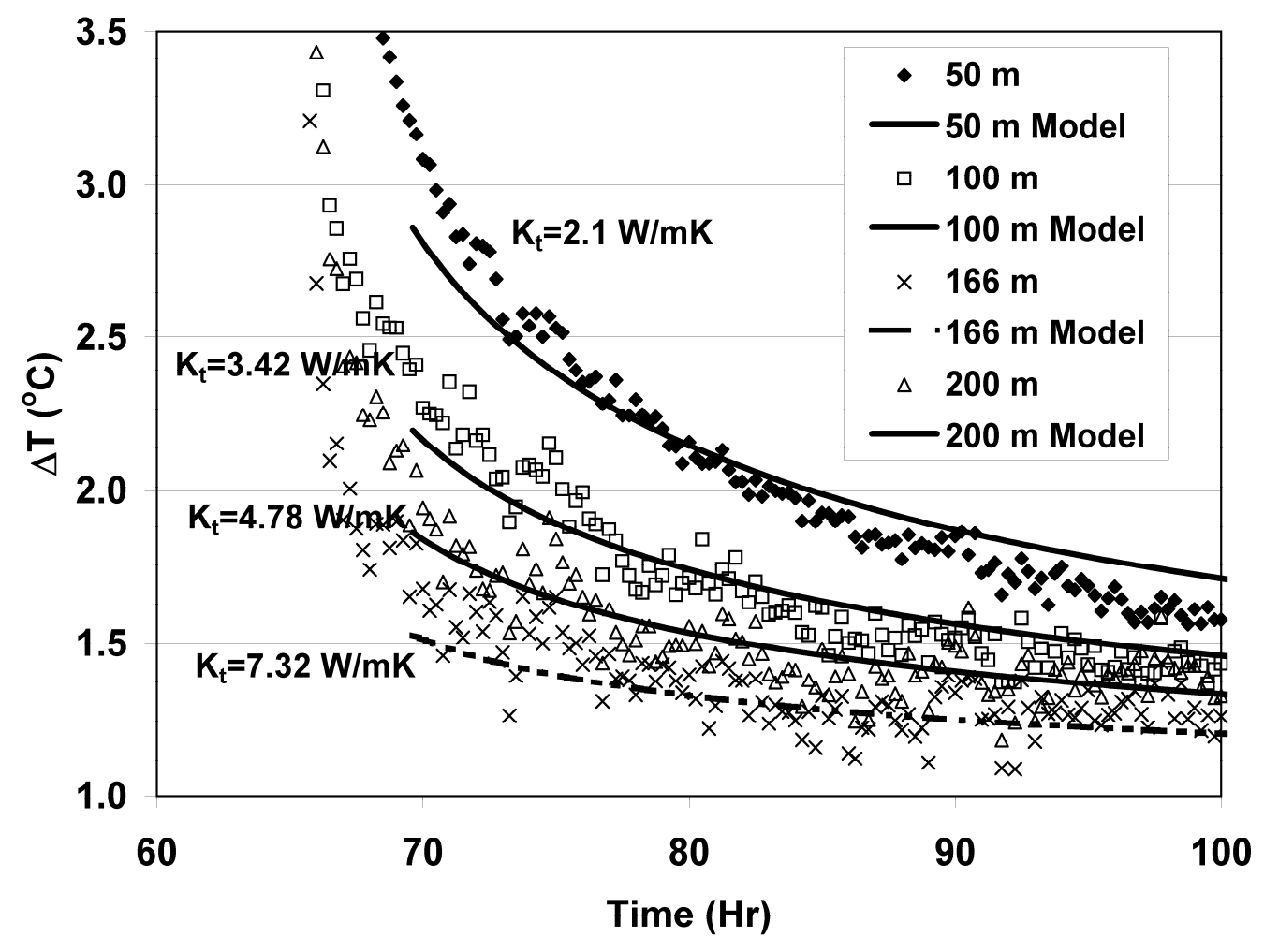

Figure 2. One-dimensional thermal simulations of DTPS testing showing modeled cooling transients along with select measurements. Cool down was initiated 64 hours after start of heating. 


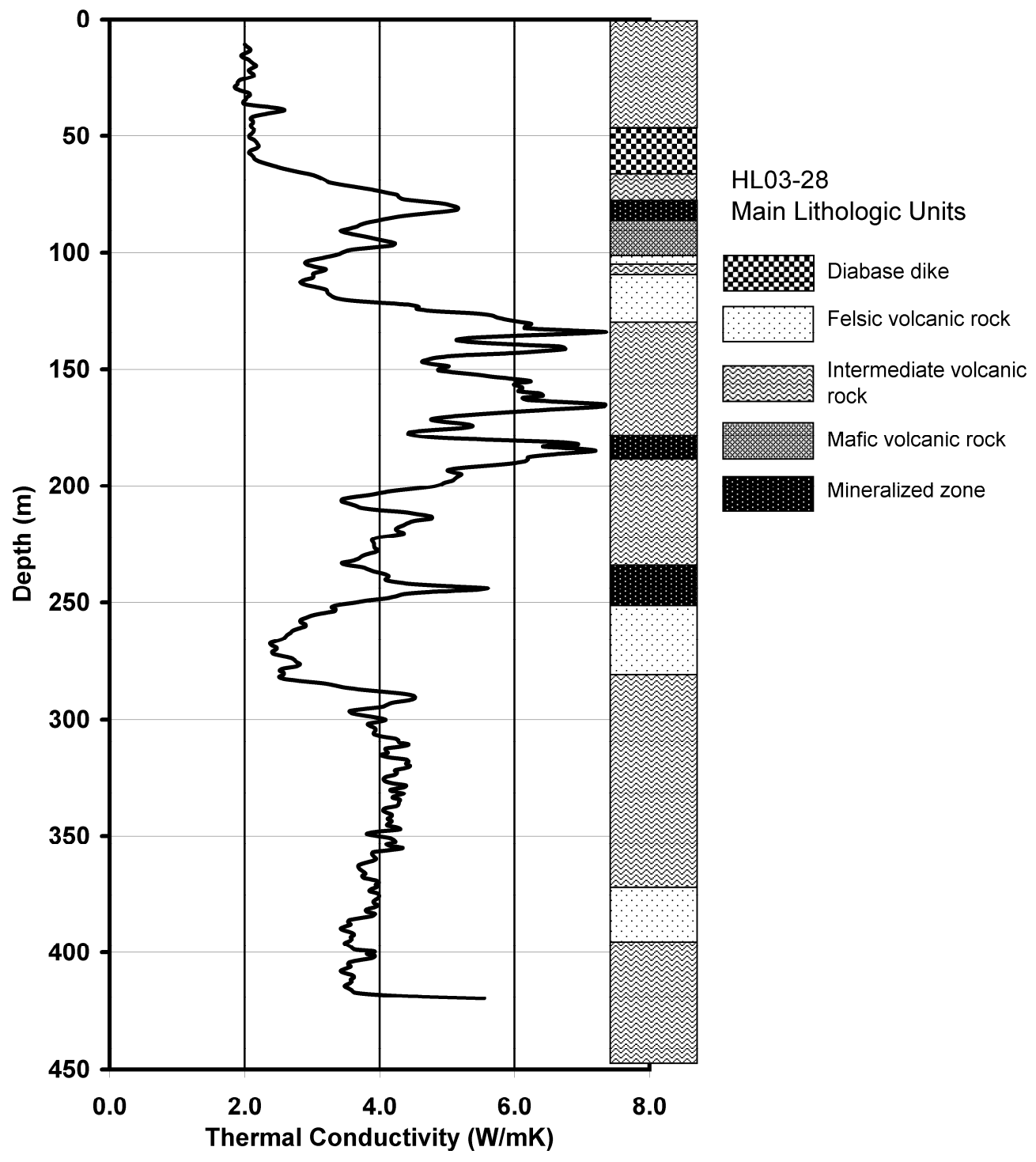

Figure 3. Thermal conductivity as a function of depth using a 1-D model to invert DTPS data and main lithologic units. Elevated thermal conductivities correspond to regions with significant sulfide mineralization. 


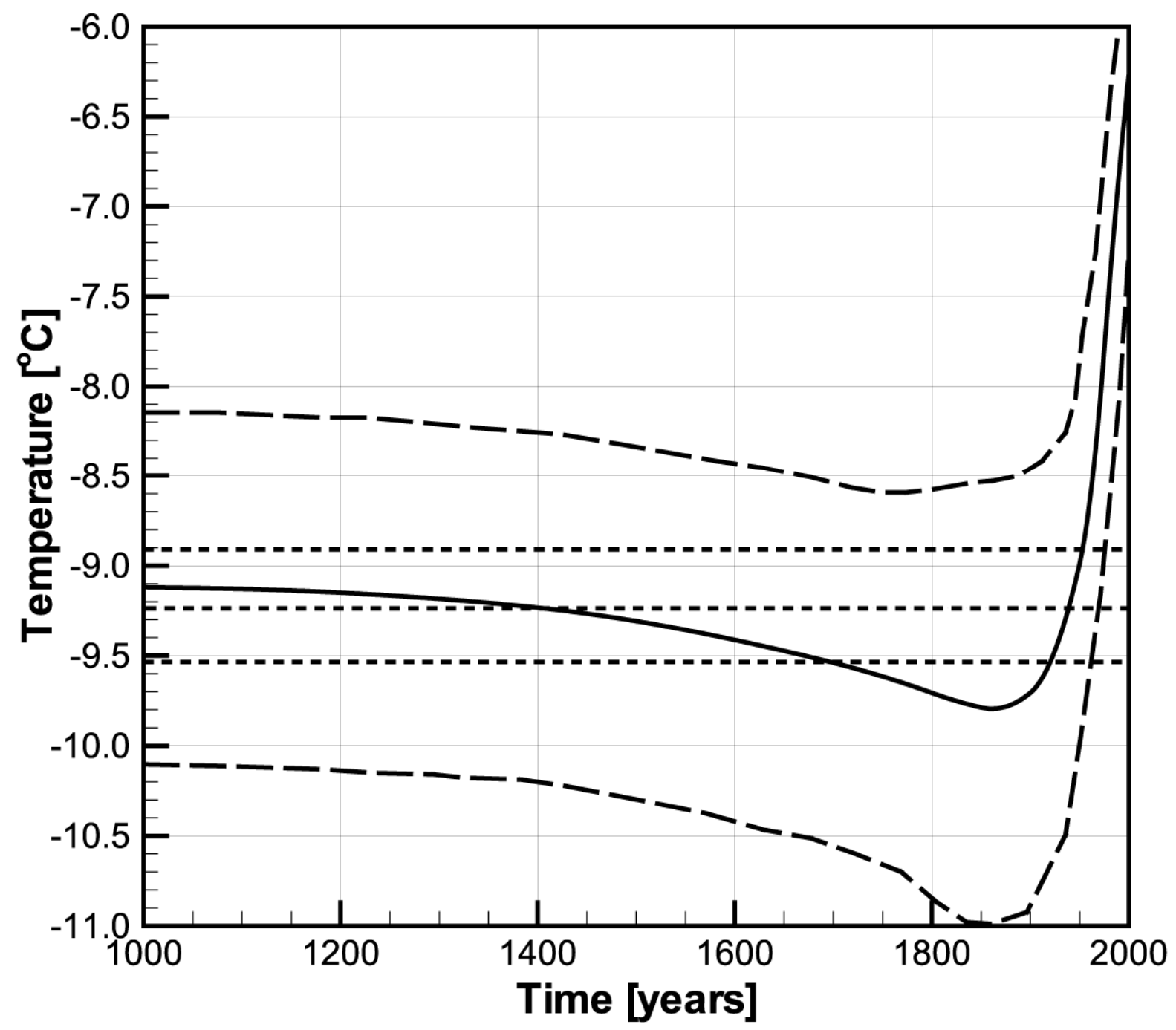

Figure 4. Estimated ground surface temperature history (solid line) with 95\% error band; estimated long-term average (dashdotted) line with $95 \%$ uncertainty band. 